In conclusion, our findings indicate that ELISPOT assays of PBMCs and CSF-MCs are useful adjuncts to current tests for diagnosing TBM. The PBMC ELISPOT assay combined with CSF ADA is a useful rapid rule-out test and the CSF-MC/PBMC ELISPOT ratio is an accurate rule-in test.

K-H. Park*, O-H. Cho*, E.M. Lee", S-O. Lee*, S-H. Choi*, Y.S. Kim*, J.H. Woo*, J.K. Kang ${ }^{*}$, S-A. Lee ${ }^{\text {\% }}$ and S-H. Kim* *Depts of Infectious Diseases and "Neurology, Asan Medical Center, University of Ulsan College of Medicine, Seoul, and "Dept of Neurology, Ulsan University Hospital, University of Ulsan College of Medicine, Ulsan, Republic of Korea.

Correspondence: S-H. Kim, Dept of Infectious Diseases, Asan Medical Center, University of Ulsan College of Medicine, 86 Asanbyeongwon-gil, Songpa-gu, Seoul 138-736, Republic of Korea. E-mail: kimsunghanmd@hotmail.com

Support Statement: This letter was supported by the National Research Foundation of Korea (NRF) funded by the Ministry of Education, Science and Technology (grant number: 2010-0005898).

Statement of Interest: None declared.

\section{REFERENCES}

1 Kim SH, Cho OH, Park SJ, et al. Rapid diagnosis of tuberculous meningitis by $\mathrm{T}$ cell-based assays on peripheral blood and cerebrospinal fluid mononuclear cells. Clin Infect Dis 2010; 50: 1349-1358.

2 Patel VB, Singh R, Connolly C, et al. Cerebrospinal T-cell responses aid in the diagnosis of tuberculous meningitis in a human immunodeficiency virus- and tuberculosis-endemic population. Am J Respir Crit Care Med 2010; 182: 569-577.

3 Marais S, Thwaites G, Schoeman JF, et al. Tuberculous meningitis: a uniform case definition for use in clinical research. Lancet Infect Dis 2010; 10: 803-812.

4 Kim SH, Choi SJ, Kim HB, et al. Diagnostic usefulness of a T-cell based assay for extrapulmonary tuberculosis. Arch Intern Med 2007; 167: 2255-2259.

5 Jafari C, Ernst M, Strassburg A, et al. Local immunodiagnosis of pulmonary tuberculosis by enzyme-linked immunospot. Eur Respir J 2008; 31: 261-265.

6 Jafari C, Lange C. Suttons's law: local immunodiagnosis of tuberculosis. Infection 2008; 36: 510-514.

7 Kosters K, Nau R, Bossink A, et al. Rapid diagnosis of CNS tuberculosis by a T-cell interferon- $\gamma$ release assay on cerebrospinal fluid mononuclear cells. Infection 2008; 36: 597-600.

8 Dheda K, van Zyl-Smit RN, Sechi LA, et al. Utility of quantitative T-cell responses versus unstimulated interferon- $\gamma$ for the diagnosis of pleural tuberculosis. Eur Respir J 2009; 34: 1118-1126.

9 Burgess LJ, Reuter H, Carstens ME, et al. The use of adenosine deaminase and interferon- $\gamma$ as diagnostic tools for tuberculous pericarditis. Chest 2002; 122: 900-905.

10 Sharma SK, Tahir M, Mohan A, et al. Diagnostic accuracy of ascitic fluid IFN- $\gamma$ and adenosine deaminase assays in the diagnosis of tuberculous ascites. J Interferon Cytokine Res 2006; 26: 484-488.

DOI: $10.1183 / 09031936.00098111$

\title{
On linezolid efficacy and tolerability
}

\section{To the Editors:}

To further comment on the safety, tolerability and efficacy profile of linezolid in treating "difficult" tuberculosis (TB) cases, following the recent study by VILLAR et al. [1], we here report on the experience of the E. Morelli Hospital in Sondalo, Italy, a reference centre for difficult-to-treat TB cases, e.g. those affected by multidrug-resistant (MDR)- and extensively drug-resistant (XDR)-TB, located in northern Italy [2-3].

As reported elsewhere [3], linezolid has been prescribed "off label" in Sondalo, Italy since 2005 to treat patients for whom at least four active drugs cannot be ensured, according to World Health Organization recommendations [4].

Administration of linezolid, within regimens designed to balance efficacy and tolerability, needs to be guided by clear scientific evidence focused on the ideal dosage (per $\mathrm{kg}$ body weight per day) and duration [1, 5-9].

The aim of this letter is to describe our recent experience of linezolid tolerability and efficacy between 2009 and 2010.

Methods and definitions are consistent with those used in previous studies by our group $[1,6]$.

MDR- and XDR-TB have been defined, respectively, as in vitro resistance to at least isoniazid and rifampicin (the two most potent first-line drugs for TB treatment) and resistance to isoniazid and rifampicin plus any fluoroquinolone and at least one of the injectable drugs amikacin, capreomycin or kanamycin.

The main results of this study are summarised in tables 1-3.

$\begin{array}{ll}\text { TABLE } 1 & \begin{array}{l}\text { Epidemiological characteristics of } 12 \text { patient } \\ \text { with multidrug-resistant/extremely drug-resist } \\ \text { (XDR) tuberculosis (TB) treated with linezo } \\ \text { Sondalo, Italy }\end{array} \\ & 4 / 12(33) \\ \text { XDR-TB } & 10 / 12(83) \\ \text { Resistance to streptomycin } & 9 / 12(75) \\ \text { Resistance to ethambutol } & 9 / 12(75) \\ \text { Resistance to pyrazinamide } & 7 / 12(58) \\ \text { Resistance to fluoroquinolones } & 3 / 12(25) \\ \text { Resistance to amikacin } & 6 / 11(54) \\ \text { Resistance to kanamycin } & 3 / 11(27) \\ \text { Resistance to capreomycin } & 9 / 12(75) \\ \text { Previous exposure to anti-TB } & \\ \quad \text { therapy }>\mathbf{3 0} \text { days } & 2(0.5-8) \\ \text { Median (IQR) number of times } & \end{array}$

Data are presented as $\mathrm{n} / \mathrm{N}(\%)$, unless otherwise stated. IQR: interquartile range. 


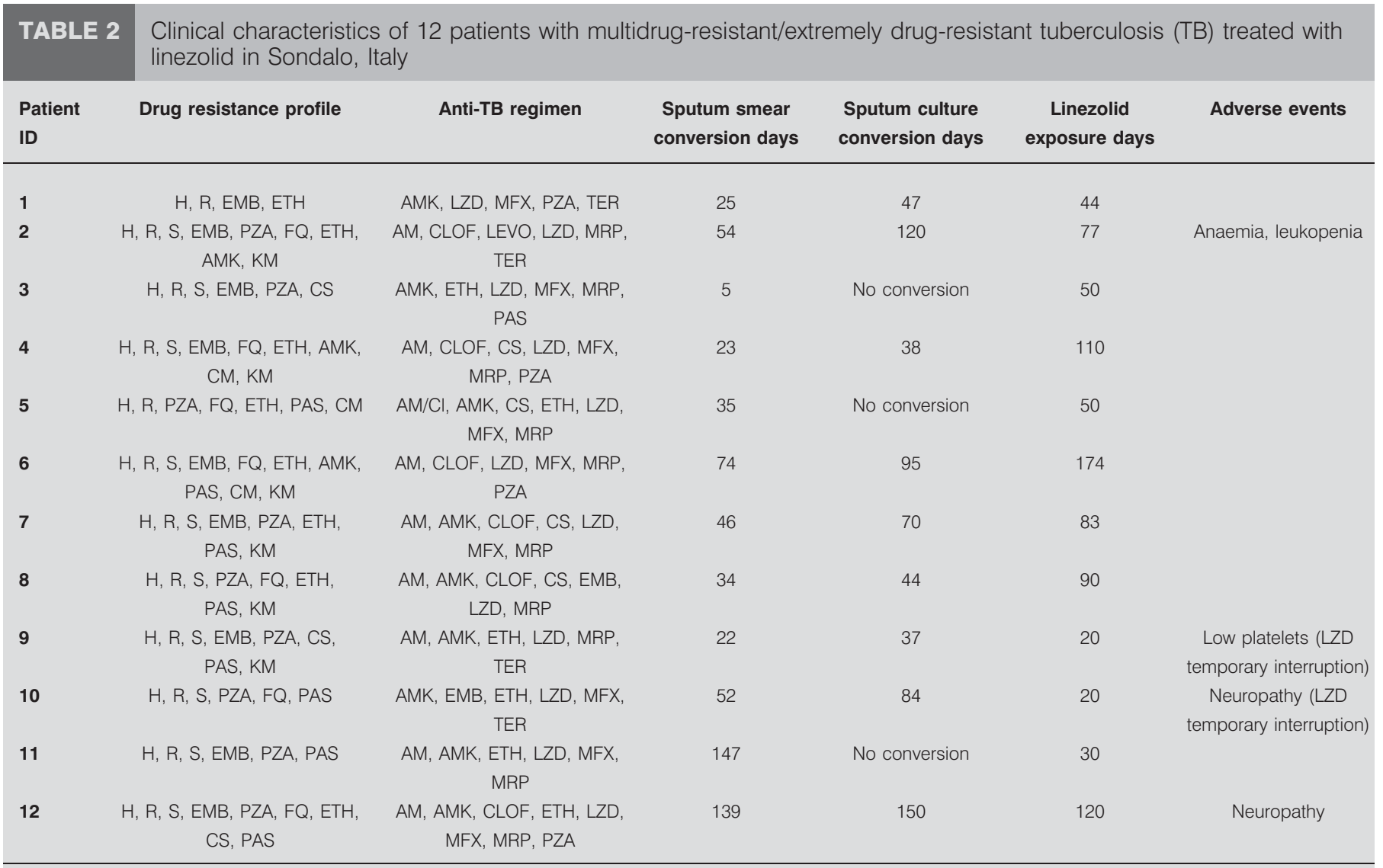

AM: amoxicillin; AM/Cl: amoxicillin/clavulanate acid; AMK: amikacin; CLOF: clofazimine; CM: capreomycin; CS: cycloserine; EMB: ethambutol; ETH: ethionamide; FQ: any fluoroquinolone; H: isoniazid; KM: kanamycin; LEVO: levofloxacin; LZD: linezolid; MFX: moxifloxacin; MRP: meropenem; PAS: $p$-aminosalicylic acid; PZA: pyrazinamide; R: rifampicin; S; streptomycin; TER: terizidone.

The features of the Sondalo cohort cases (table 1) are substantially similar to those illustrated by VILLAR et al. [1], the prevalence of resistance to first-line anti-TB drugs being similar, the prevalence of resistance to XDR-TB-defining drugs slightly lower and the proportion of previous exposure to anti-TB drugs (as well as the number of previous anti-TB treatment exposures $>30$ days) slightly higher.

The majority of the cases (11 (91.7\%) out of 12$)$ were migrants from high MDR-TB burden countries (six from Romania, two from Ukraine, one from Moldova, one from Pakistan and one from India) versus almost one-third (five (31.3\%) out of 16; $\mathrm{p}=0.0014)$ reported in Portugal [1].

In our cohort, linezolid was administered for a median (interquartile range (IQR)) time of 63.5 (37-100) days with a dosage of $600 \mathrm{mg}$ twice a day for the majority (10 (83.3\%) out of 12) of the cases, while two patients were prescribed $600 \mathrm{mg}$ once daily and $450 \mathrm{mg}$ twice a day, respectively.

All patients were males, with a mean \pm SD age of $40 \pm 9.2$ yrs. Two cases were HIV infected and were treated with antiretroviral

TABLE 3 Comparison of 12 patients with multidrug-resistant/extremely drug-resistant tuberculosis treated with linezolid in Sondalo with two other recently published cohorts

\begin{tabular}{lcccc} 
& Sondalo cohort & MIGLIORI [3] & p-value & VILLAR [1] \\
\hline $\begin{array}{l}\text { Time to sputum smear } \\
\text { conversion days }\end{array}$ & $40.5(24-64)$ & $76(56-162)$ & 0.0101 & $150(60-540)$ \\
$\begin{array}{l}\text { Time to culture } \\
\text { conversion days }\end{array}$ & $70(44-95)$ & $108(56-160)$ & 0.1865 & $180(90-1380)$ \\
\hline
\end{tabular}

Data are presented as median (interquartile range), unless otherwise stated. ${ }^{\#}$ : comparison between Sondalo and MigLIORI [3] cohorts; ": comparison between Sondalo and VILLAR [1] cohorts. 
drugs, while two patients underwent surgery in addition to chemotherapy.

As in other reference centres, the E. Morelli Hospital needs to transfer out all admitted cases to the hospitals referring them for specialised treatment, when culture conversion and clinical stability have been achieved. Patients were transferred out after a median (IQR) hospital stay of 75.5 (51.5-127.5) days; 12 (100\%) out of 12 and nine (75\%) out of 12 achieved sputum-smear and culture conversion, after a median (IQR) time of 40.5 (24-64) and 70 (44-95) days, respectively. As of June 2011, one patient was cured, two had died and nine were still under treatment.

Four $(33.3 \%)$ cases reported adverse events, two being major (16.7\%; neuropathy and low platelet count, needing temporary interruption of linezolid) and two minor (neuropathy and mild anaemia). All adverse events were reversible.

In conclusion, despite the intrinsic difficulty of evaluating the safety and tolerability of linezolid (administered within different regimens including multiple anti-TB drugs guided by drug susceptibility testing), the study results are consistent with the findings described by VILLAR et al. [1] and SCHECTER et al. [10]. Based on the results of the study, the dose of linezolid has been reduced in Sondalo from a minimum of 450 to a maximum of $600 \mathrm{mg} \cdot$ day $^{-1}$ (determined by kinetics performed on all cases).

At present, a systematic review including information from the patients treated with linezolid globally is probably the easiest option to better define the efficacy, safety and tolerability of the drug in the treatment of MDR-/XDR-TB.

\section{S. De Lorenzo*, R. Centis", L. D’Ambrosio", G. Sotgiu" and G.B. Migliori"}

*E. Morelli Hospital, Reference Hospital for MDR and HIV TB, Sondalo, "World Health Organization Collaborating Centre for Tuberculosis and Lung Diseases, Fondazione S. Maugeri, Care and Research Institute, Tradate, and "Dept of Biomedical Sciences, University of Sassari, Sassari, Italy.

Correspondence: G.B. Migliori, World Health Organization Collaborating Centre for Tuberculosis and Lung Diseases, Fondazione S. Maugeri, Care and Research Institute, Via
Roncaccio 16, 21049, Tradate, Italy. E-mail: giovannibattista. migliori@fsm.it

Support Statement: This study was supported by the current research funds of the participating institutions. For this publication, the research leading to these results has received funding from the European Community's Seventh Framework Programme (FP7/2007-2013) under grant agreement FP7223681.

Statement of Interest: None declared.

\section{REFERENCES}

1 Villar M, Sotgiu G, D'Ambrosio L, et al. Linezolid safety, tolerability and efficacy to treat multidrug- and extensively drug-resistant tuberculosis. Eur Respir J 2011; 38: 730-733.

2 World Health Organization. Multidrug and extensively drug resistant TB (M/XDR-TB): 2010 global report on surveillance and response. Publication No. WHO/HTM/TB/2010.3. Geneva, World Health Organization, 2010.

3 Migliori GB, Besozzi G, Girardi E, et al. Clinical and operational value of the extensively drug-resistant tuberculosis definition. Eur Respir J 2007; 30: 623-626.

4 Falzon D, Jaramillo E, Schünemann HJ, et al. WHO guidelines for the programmatic management of drug-resistant tuberculosis: 2011 update. Eur Respir J 2011; 38: 516-528.

5 Sotgiu G, Ferrara G, Matteelli A, et al. Epidemiology and clinical management of XDR-TB: a systematic review by TBNET. Eur Respir J 2009; 33: 871-881.

6 Migliori GB, Eker B, Richardson MD, et al. A retrospective TBNET assessment of linezolid safety, tolerability and efficacy in multidrug-resistant tuberculosis. Eur Respir J 2009; 34: 387-393.

7 Yew WW, Lange C, Leung CC. Treatment of tuberculosis: update 2010. Eur Respir J 2011; 37: 441-462.

8 Yew WW, Chang KC, Chau CH. What is the optimal dosage of linezolid in treatment of complicated multidrug-resistant tuberculosis? Eur Respir J 2009; 34: 1492-1494.

9 Udwadia ZF, Sen T, Moharil G. Assessment of linezolid efficacy and safety in MDR- and XDR-TB: an Indian perspective. Eur Respir J 2010; 35: 936-938.

10 Schecter GF, Scott C, True L, et al. Linezolid in the treatment of multidrug-resistant tuberculosis. Clin Infect Dis 2010; 50: 49-55.

\section{Octreotide treatment of idiopathic pulmonary fibrosis: a proof-of-concept study}

\section{To the Editors:}

Idiopathic pulmonary fibrosis (IPF) is the most frequent form of idiopathic interstitial pneumonia. It is a chronic, progressive and fatal disease of unknown aetiology, characterised by histological features of usual interstitial pneumonia (UIP). Disease progression is marked by worsening dyspnoea, progressive loss of lung volume, abnormal gas exchange and poor quality of life. Median survival after diagnosis is $3-5$ yrs. Currently, pirfenidone is the only drug approved in Europe for the treatment in IPF, as it has been shown to slow the decline of lung function [1]. However, no effect on survival has been demonstrated until now.

Somatostatin is an endogenous cyclic peptide initially identified as a regulator of growth hormone secretion. In humans, it has been shown to bind with equal efficiency to five receptors: sst1, sst2A, sst3, sst4 and sst5. We have recently shown that the sst2A receptor is highly expressed in fibrotic lung tissue in IPF patients 